J. Lake Sci. (湖泊科学), 2006, 18(3):299-304

http:// www. jlakes. org. E-mail: jlakes@ niglas. ac.cn

(c) 2006 by Journal of Lake Sciences

\title{
湖北牛山湖小型鱼类的群落结构及多样性”
}

\author{
冯广朋 ${ }^{1,2,3}$, 李钟杰 ${ }^{1 * *}$, 谢从新 ${ }^{2}$, 叶少文 ${ }^{1,4}$ \\ (1: 中国科学院水生生物研究所, 武汉 430072) \\ ( 2 : 华中农业大学水产学院,武汉 430070) \\ (3: 中国水产科学研究院东海水产研究所, 上海 200090) \\ (4:中国科学院研究生院, 北京 100039)
}

摘 要: 研究了牛山湖小型鱼类的群落结构、种群密度和多样性. 共捕获 14 种小型鱼类, 以 1 龄鱼为主, 其 中红鳀原鲌、似鱎、麦穂鱼和鳑鲏是优势种群. 小型鱼类的密度为 $5.9 \mathrm{ind} / \mathrm{m}^{2}$ 或 $14.0 \mathrm{~g} / \mathrm{m}^{2}$. 小型鱼类的群 落多样性较低, 以个体数为单位计算的 Shannon-Wiener 多样性指数为 1.802 , Simpson 优势度指数为 0.484 , Pielou 种类均匀度指数为 0.503 . 水生植被是牛山湖小型鱼类群落分布的主要影响因子,水草生境中小型 鱼类数量显著比无水草生境中多, 水深和透明度对小型鱼类群落分布无显著性影响. 通过合理调控湖泊鱼 类群落结构和放养食鱼性鱼类来合理持续利用小型鱼类, 有利于提高湖泊经济效益和生态效益.

关键词: 小型鱼类;群落结构;多样性; 牛山湖

\section{Structure and diversity of small-sized fish community in Lake Niushan, Hubei Province}

FENG Guangpeng ${ }^{1,2,3}$, LI Zhongjie ${ }^{1 * *}$, XIE Congxin ${ }^{2} \&$ YE Shaowen ${ }^{1}$

(1: Institute of Hydrobiology, Chinese Academy of Sciences, Wuhan 430072, P. R. China)

(2: College of Fisheries, Huazhong Agriculture University, Wuhan 430070, P. R. China)

(3: East China Sea Fisheries Research Institute, CAFS, Shanghai 200090,P. R. China)

(4: Graduate School of the Chinese Academy of Sciences, Beijing 100039, P. R. China)

Abstract: This paper investigated community structure, density and diversity of small-sized fish with seine in Lake Niushan, Hubei Prowince. 14 species were collected. Cultrichthys erythropterus, Taxabramis swinhonis, Pseudorasbora parva, and Acheilognathinae, including Rhodeus ocellatus, R. lighti and Paracheilognathus imberbis, were the dominant species. Majority of small-sized fishes were one year old. The density of small-sized fishes in the seine was about $5.8 \mathrm{ind} / \mathrm{m}^{2}$ or $14.0 \mathrm{~g} / \mathrm{m}^{2}$. Diversity of fish community in the seine was low. The diversity $\operatorname{index}\left(H^{\prime}\right)$, dominance $\operatorname{index}(\lambda)$ and evenness index $\left(J^{\prime}\right)$ of small-sized fish community were $1.802,0.484$ and 0.503 respectively. The macrophyte played an important role in determining the distribution of fish community. The biomass of small-sized fishes in the macrophyte regions was significantly higher than it in the regions without macrophyte. There was no significant effect of depth and transparence on the distribution of small-sized fish community in the Lake Niushan. Small-sized fish can be use reasonably, in order to increase economic and ecological benefit, through optimizing fish community structure and enhancing piscivorous fish.

Keywords : Small-sized fish; community structure; diversity; Lake Niushan

我国东部平原湖区湖泊众多, 总面积达 2 万多平方公里, 约占全国湖泊总面积的 $1 / 3$, 尤其是长江中下

* 国家“十五”重点科技攻关项目 (2004BA526B0502) 和湖北省“十五”重大科技攻关项目 (2004AA201A) 联合资助. $2005-06-17$ 收稿; $2005-11-21$ 收修改稿. 冯广朋,男,1977 年生, 硕士.

** 通讯作者; E-mail: zhongjie@ihb. ac.cn. 
游地区的湖泊一直是我国淡水渔业的重要基地, 具有巨大的渔产潜力, 传统的大水面放养以鲤科鱼类为主, 常导致湖泊水草减少和水质富营养化. 一些研究表明通过放养食鱼性鱼类利用营养级串联效应可改善湖 泊水质 ${ }^{[1,2]}$, 并可提高经济效益, 因此是解决这类湖泊渔业发展和水质保护矛盾的重要途径. 小型鱼类是食 鱼性鱼类的主要饵料生物, 研究其群落结构、种群密度和多样性是发展食鱼性鱼类渔业的重要基础. 本文 采用围网研究牛山湖小型鱼类的群落特征, 旨在为该湖泊的渔业资源合理持续利用提供依据, 也为长江中 下游地区湖泊渔业的结构调整和食鱼性鱼类的渔业发展积累资料.

\section{1 材料与方法}

\section{1 研究位置}

牛山湖 $\left(30^{\circ} 19^{\prime} \mathrm{N}, 114^{\circ} 32^{\prime} \mathrm{E}\right)$ 位于湖北省武汉市江夏区, 面积为 $4000 \mathrm{hm}^{2}$, 原为梁子湖水系的一部分, 1979 年筑堤后与梁子湖分开. 牛山湖渔场现用多层渔网将全湖隔成东片、中片和西片, 湖水能进行交换, 而 鱼类基本上被隔开 (图 1). 牛山湖水草茂密, 水质理化性状良好, 属中营养型, 是我国长江中下游地区较有 代表性的浅水草型湖泊.

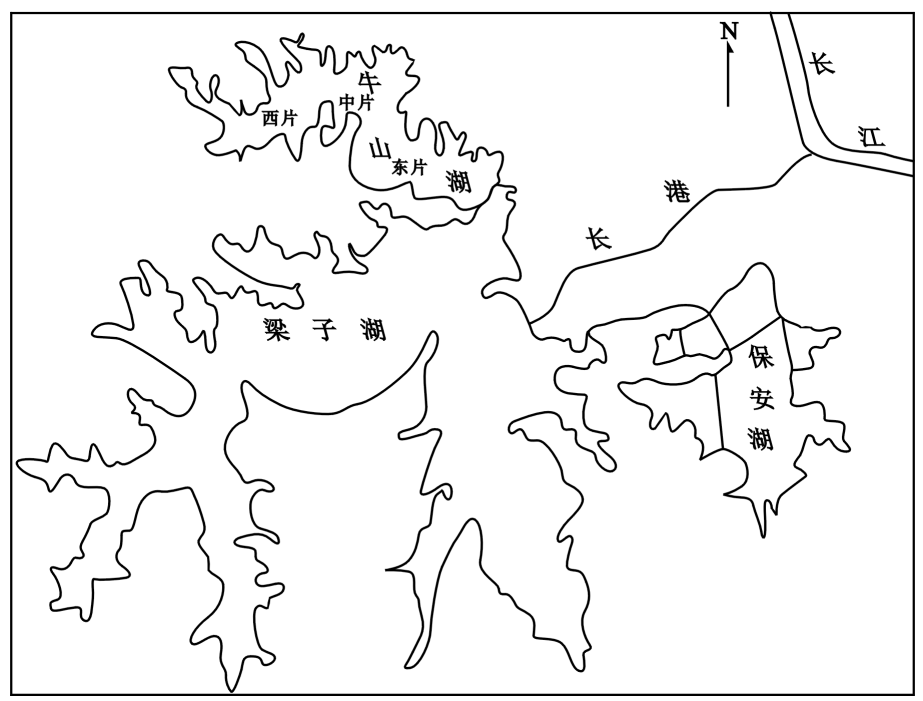

图 1 牛山湖位置示意图

\section{2 采样方法}

Fig. 1 Map of Lake Niushan, Hubei Province

鱼类生境的研究用延绳法测量水深,用萨氏盘测量透明度,用夹草器采集水草鉴别种类, 用 $1 / 16 \mathrm{~m}^{2}$ 改 良型彼德森采泥器采集底泥. 小型鱼类的研究通过围网进行采样, 以便定量研究其种群密度和群落结构. 围网上纲穿浮子, 下纲包上小石子或铁块. 三个围网长 $60-100 \mathrm{~m}$, 高 $5 \mathrm{~m}$, 网目分别为 $1.5 \mathrm{~cm} 、 2.0 \mathrm{~cm} 、 2.5$ $\mathrm{cm}$, 围网连接一个网篓来收鱼. 先对围网采样点的生境进行采样, 在下围网时尽量成圆形, 在围网的相对方 向开 3-5 m 宽的两个口, 使鱼自由进出. 围网在湖中静置 24-48 h 后, 利用装置在远处快速关闭开口, 尽 量减少对围网中鱼类的惊动, 在随后的 $5-7 \mathrm{~d}$ 中每天定时收集围网网筙中的鱼类. 渔获物分种类计数, 测 量体长和体重, 并随机抽样取鳞片鉴定年龄. 围网采样从 2002 年 6 月至 2003 年 1 月采样, 在一个月内轮流 对三片采样一次,每次用三个围网同时在一个片区采样.

\section{3 计算方法}

1.3 .1 鱼类种群数量估算 采用 Zippin 去除法估算 ${ }^{[3]}$ : 


$$
R=\frac{\sum\left[(t-1) C_{t}\right]}{\sum C_{t}} ; \quad \hat{N}=\frac{\sum C_{t}}{1-\hat{q}^{t}}
$$

式中, $C_{t}$ 是第 $t$ 次捕捞时的渔获物数量, $t$ 是连续捕捞次数, 先根据每次渔获物数量用公式一计算系数 $R$ 值, 通过 Zippin 的 $R-\left(1-\hat{q}^{t}\right)$ 图得出 $\left(1-\hat{q}^{t}\right)$ 值, 再用公式二得出围网中每种鱼的数量, 结合围网的面积即可 得出样方中鱼类种群的密度.

\section{3 .2 鱼类群落多样性指数 Shannon-Wiener 多样性指数 $H^{\prime}=-\sum p_{i} \ln p_{i}$;}

Simpson 优势度指数 $\lambda=\sum p_{i}^{2}$;

Pielou 种类均匀度指数 $J^{\prime}=H^{\prime} / H_{\text {max }}^{\prime}$.

式中, $p_{i}=N_{i} / N$, 即第 $i$ 物种占总数的比例. $H_{\text {max }}^{\prime}=\ln S$, 即在给定物种数 $S$ 下的完全均匀群落的多样性.

\section{4 数据处理}

通过统计分析软件 STATISTICA6. 0 进行相关数据分析并作图.

\section{2 结果}

\section{1 牛山湖鱼类的生境}

牛山湖东片大型水生植物的优势种类为狐尾草和黄丝草, 中片为大刺藻和狐尾草, 西片为大刺藻、狐尾 草和黄丝草, 三片平均生物量 (鲜重) 分别为 $416 、 73$ 和 $1156 \mathrm{~g} / \mathrm{m}^{2}$, 差别较大. 三片底质都以淤泥为主. 水深 和透明度以中片最大, 东片次之, 西片最小, 但差别较小. 三片水深都在 $3-5 \mathrm{~m}$, 透明度 $2 \mathrm{~m}$ 以上. 因此牛山 湖的大型水生植物生物量较高, 是个水质较好的浅水草型湖泊.

\section{2 小型鱼类的群落组成和体长体重分布}

围网渔获物由 14 种小型鱼类组成,包括红鯺原鲌、黑鯺鳈、棒花鱼、似鱎、餐、麦穗鱼、刺䱊、鳑鲏(包括 高体鳑鲏、彩石鳑鲏、彩副鱊）、黄颡鱼、黄秘、鲫、沙塘鳢等, 以鲤科鱼类为主. 渔获物中超过 400 尾的鱼类 有红鯺原鲌、似鱎、麦穗鱼和鰟鲏, 它们是小型鱼类群落的优势种群. 渔获物中鱼类体长和体重一般都较 小,除红鯺原鲌和刺鳅外,其余小型鱼类的平均体长小于 $91 \mathrm{~mm}$,平均体重小于 $20.5 \mathrm{~g}$ (表 1$)$.

\section{表 1 小型鱼类体长和体重的分布}

Tab. 1 Distribution of body length and body weight of small-sized fishes

\begin{tabular}{lccccccc}
\hline 鱼类 & $\begin{array}{c}\text { 尾数 } \\
(\mathrm{ind})\end{array}$ & $\begin{array}{c}\text { 重量 } \\
(\mathrm{g})\end{array}$ & $\begin{array}{c}\text { 体长范围 } \\
(\mathrm{mm})\end{array}$ & $\begin{array}{c}\text { 平均体长 } \\
(\mathrm{mm})\end{array}$ & $\begin{array}{c}\text { 体重范围 } \\
(\mathrm{g})\end{array}$ & $\begin{array}{c}\text { 平均体重 } \\
(\mathrm{g})\end{array}$ \\
\hline 红鯺原鲌 Cultrichthys erythropterus & 578 & 106443.6 & $10-200$ & 105 & $0.3-264.0$ & 184.2 \\
黑鮱鳈 Sarcocheilichthys nigripinnis & 180 & 767.7 & $31-98$ & 64 & $0.6-22.1$ & 4.3 \\
棒花鱼 Abbottina rivularis & 182 & 336.9 & $26-79$ & 48 & $0.2-9.5$ & 1.9 \\
似鱎 Taxabramis swinhonis & 416 & 1193.6 & $24-95$ & 67 & $0.2-7.0$ & 2.9 \\
䱗 Hemiculter leucisculus & 118 & 838.8 & $22-157$ & 79 & $0.4-58.2$ & 7.1 \\
麦穗鱼 Pseudorasbora parva & 531 & 667.0 & $19-76$ & 41 & $0.1-10.1$ & 1.3 \\
刺鲉 Mastacembelus aculeatus & 56 & 478.5 & $20-208$ & 150 & $3.0-24.5$ & 8.5 \\
鳑鲏 Acheilognathinae & 5342 & 5616.4 & $18-85$ & 45 & $0.2-12.1$ & 1.1 \\
黄颡鱼 Pseudobagrus fulvidraco & 30 & 348.9 & $44-187$ & 76 & $1.4-91.4$ & 11.6 \\
黄黝 Hypseleotris swinhonis & 385 & 242.9 & $17-43$ & 31 & $0.1-1.4$ & 0.6 \\
鲫 Carassius auratus & 33 & 34.2 & $34-66$ & 47 & $1.1-8.2$ & 5.0 \\
沙塘鳢 Odontobutis obscura & 3 & 61.5 & $83-100$ & 91 & $13.4-24.6$ & 20.5 \\
\hline
\end{tabular}

\section{3 主要优势鱼类的年龄结构}

围网中的主要优势鱼类麦穂鱼、黑鯺鳈、似鱎、棒花鱼和红鯺原鲌都以 1 龄鱼为主,其中麦穂鱼、黑鯺鳈 和似鱎的种群只由 1 龄鱼组成, 而棒花鱼和红鲑原鲌中 2 龄鱼数量也相对较少 (表 2). 
表 2 牛山湖主要优势鱼类的年龄组成

Tab. 2 Age structure of main small-sized fishes in Lake Niushan

\begin{tabular}{|c|c|c|c|c|c|}
\hline 鱼类 & \multicolumn{5}{|c|}{ 总尾数 $($ ind $) 1$ 龄鱼 $($ ind $)$ 平均体长 $(\mathrm{mm}) 2$ 龄鱼 $($ ind $)$ 平均体长 $(\mathrm{mm})$} \\
\hline 麦穂鱼 Pseudorasbora parva & 116 & 116 & 50 & & \\
\hline 棒花鱼 Abbottina rivularis & 111 & 110 & 48 & 1 & 78 \\
\hline 黑鳍鳈 Sarcocheilichthys nigripinnis & 89 & 89 & 66 & & \\
\hline 似鱎 Taxabramis swinhonis & 98 & 98 & 63 & & \\
\hline 红鯺原鲌 Cultrichthys erythropterus & 578 & 487 & 99 & 91 & 151 \\
\hline
\end{tabular}

\section{4 小型鱼类群落的多样性}

牛山湖小型鱼类群落多样性较低, 以个体数为单位计算的 Shannon-Wiener 多样性指数 $H^{\prime}$ 为 1.802 , Simpson 优势度指数 $\lambda$ 为 0.484 , Pielou 种类均匀度指数 $J$, 为 0.503 . 以生物量为计算单位, 则 $H$, 为 0.653 , $\lambda$ 为 $0.830, J$, 为 0.182 . 以生物量为计算单位的 $H^{\prime}$ 和 $J$, 值比以个体数为计算单位的 $H^{\prime}$ 低, 而 $\lambda$ 值比以个体 数为计算单位的高.

\section{5 小型鱼类的种群密度}

以渔获物数量计算,围网中鱼类密度为 $5.9 \mathrm{ind} / \mathrm{m}^{2}$. 其中鳑鲏的密度最大, 黑鯺鳈次之. 以渔获物重量 计算, 围网中鱼类密度为 $14.0 \mathrm{~g} / \mathrm{m}^{2}$, 黑鳀鳈的密度最大,鳑鲏次之(表 3). 棒花鱼和刺䱊的数量在被捕获过 程没有随天数的增加而减少,用 Zippin 去除法不能估算. 而沙塘鳢因数量太少亦不能被估算.

表 3 用 Zippin 法估算牛山湖 $10000 \mathrm{~m}^{2}$ 水体中小型鱼类数量和生物量

Tab. 3 Estimated number and abundance of small-sized fishes through Zippin's removal method in Lake Niushan

\begin{tabular}{|c|c|c|c|c|c|c|c|c|c|c|}
\hline 指标 & 红鯺原鲌 & 黑鯺鳈 & 似鱎 & 㛑 & 麦穗鱼 & 鳑鲏 & 黄颡鱼 & 黄黝 & 鲫 & 合计 \\
\hline 数量 (ind) & 344 & 16031 & 406 & 938 & 4156 & 31594 & 63 & 5031 & 125 & 58688 \\
\hline 重量 $(\mathrm{g})$ & 4472 & 80155 & 771 & 2626 & 6234 & 41072 & 533 & 4025 & 250 & 140138 \\
\hline
\end{tabular}

\section{6 小型鱼类群落的空间分布}

以东片、西片和中片 3 个湖区为协变量,分别以透明度和水深为自变量,采用协方差分析表明透明度和 水深对围网渔获物数量没有显著的影响. 经 $t$-检验表明牛山湖各片有水草区域的小型鱼类数量显著多于 无水草区域. 牛山湖三片中, 中片的小型鱼类数量最多,西片次之,东片最少 (表 4). 中片的小型鱼类中鳑 鲏数量最多,占渔获物总尾数的 $76.4 \%$, 而其它两片红鰙原鲌和似鱎数量居多.

\section{3 讨论}

\section{1 小型鱼类群落研究采样方法的探讨}

小型鱼类一般活动范围较小,捕捞强度较低,因此常用的鱼类群落采样方法(如标志回捕法、直接分拣 计数法等) 常不适合湖泊小型鱼类群落研究, 采样方法是小型鱼类群落研究的难点之一 ${ }^{[4]}$. 本研究采用围 网法研究牛山湖小型鱼类群落, 共捕到 14 种小型鱼类, 并对其中 9 个种类进行有效的密度估算, 因此围网 是湖泊小型鱼类群落较好的采样方法. 围网采样的效率与鱼类行为有很大的关系, 一般对喜欢近岸浅水生 活的鱼类采样效果较好 ${ }^{[5]}$. 本研究中渔获物优势种群是活动能力较强的中上层小型鱼类, 因此围网主要适 用于中上层小型鱼类的采样,这和谢松光等 ${ }^{[6]}$ 研究结果相似. 在牛山湖用蹦网对小型鱼类的研究表明, 蹦 网渔获物以活动能力较低的底层鱼类为主, 其优势种群为黄䵢和子陵栉鰕虎鱼, 蹦网主要适用于底层小型 鱼类的采样 ${ }^{[7]}$. 因此围网和蹦网分别适合湖泊不同水层小型鱼类的采样研究, 两者相结合是较理想的长江 中下游浅水草型湖泊小型鱼类群落研究的采样方法. Xie 等 ${ }^{[7]}$ 在牛山湖用蹦网收到 7 种鱼, 比本研究用围 网采到的鱼类种数少, 这可能是由于围网比蹦网的采样面积大, 能捕到更多的小型鱼类. Dewey 等 $^{[8]}$ 研究 表明在有水草区域和无水草区域用围网收集到的鱼类种数比蹦网多,认为可能是由于蹦网采样的面积较小 所致, 而且蹦网主要在无水草区域采样效果较好. 
表 4 牛山湖不同生境中渔获物的数量 ${ }^{1)}$

Tab. 4 Number of fish sampled in different habitats in Lake Niushan

\begin{tabular}{ccccccc}
\hline 湖区 & 围网 & 水深 $(\mathrm{m})$ & 透明度 $(\mathrm{m})$ & 底质 & 水草 & 渔获物 $($ 尾) \\
\hline 东片 & 1 号网 & 2.4 & 1.0 & 淤泥 & 狐尾草、苦草 & 25 \\
& 2 号网 & 3.0 & 0.8 & 淤泥 & 狐尾草、苦草 & 47 \\
& 3 号网 & 3.7 & 1.1 & 淤泥 & 无 & 2 \\
中片 & 1 号网 & 1.9 & 1.9 & 淤泥 & 黄丝草 & 1085 \\
& 2 号网 & 2.3 & 2.3 & 淤泥 & 轮叶黑藻 & 825 \\
& 3 号网 & 3.4 & 2.8 & 淤泥 & 无 & 11 \\
西片 & 1 号网 & 2.5 & 2.5 & 淤泥 & 黄丝草 & 140 \\
& 2 号网 & 2.4 & 2.4 & 淤泥 & 黄丝草 & 321 \\
& 3 号网 & 3.3 & 2.0 & 淤泥 & 无 & 0 \\
\hline
\end{tabular}

1) 1 号网、2号网、3号网的网目分别为 $1.5 \mathrm{~cm} 、 2.0 \mathrm{~cm} 、 2.5 \mathrm{~cm}$.

表 5 牛山湖中片和西片的渔获物组成

Tab. 5 Fish composition of Lake Niushan in the catch

\begin{tabular}{|c|c|c|c|c|c|c|c|c|c|c|}
\hline 湖区 & 组成 & 鲫 & 鲤 & 青鱼 & 草鱼 & 乌鳢 & 团头鲂 & $\begin{array}{c}\text { 红鯺原 } \\
\text { 鲌、餐 }\end{array}$ & $\begin{array}{l}\text { 鳜、黄 } \\
\text { 颡鱼 }\end{array}$ & 小杂鱼 \\
\hline \multirow{2}{*}{ 中片 } & 重量(kg) & 14238 & 3888 & 25 & 20 & 853 & 293 & 4057 & 1668 & 290 \\
\hline & 百分比 (\%) & 56.2 & 15.3 & 0.1 & 0.1 & 3.4 & 1.2 & 16.1 & 6.6 & 1.1 \\
\hline \multirow[t]{2}{*}{ 西片 } & 重量( kg) & 3610 & 691 & 439 & 218 & 363 & 51 & 2122 & 1501 & 39 \\
\hline & 百分比 (\%) & 40.0 & 7.7 & 4.9 & 2.4 & 4.0 & 0.6 & 23.5 & 16.6 & 0.4 \\
\hline
\end{tabular}

\section{2 牛山湖小型鱼类的种群数量}

根据生境模块理论,湖泊是由不同的生境组合而成,特定的生境中生存着特定的鱼类群落. 因此湖泊 小型鱼类种群密度的研究可通过将湖泊划分为不同的生境, 分别研究这些不同生境样方中小型鱼类的种群 密度,估算出湖泊中鱼类种群的数量.

牛山湖围网中小型鱼类种群密度为 $5.8 \mathrm{ind} / \mathrm{m}^{2}$ 或 $14.0 \mathrm{~g} / \mathrm{m}^{2}$. Xie 等 ${ }^{[9]}$ 研究表明梁子湖沿岸带沉水植 物生境小型鱼类种群密度为 $5.8 \mathrm{ind} / \mathrm{m}^{2}$, 生物量为 $14.5 \mathrm{~g} / \mathrm{m}^{2}$, 因此这两个湖泊地理位置相近, 水域生态环 境条件相似,虽然 1979 年后因筑堤而分隔,但目前两湖的小型鱼类种群密度仍相近.

牛山湖三片中, 小型鱼类的数量以中片最多,西片次之,东片最少 (表 4), 这可能与不同湖区凶猛性鱼 类的数量有关. 牛山湖目前大量放养中华线鳌蟹, 渔民认为凶猛性鱼类会导致幼蟹的死亡, 因此每年都大 规模捕捞凶猛性鱼类减少其数量. 本研究表明中片的水草最少, 因此中片的网篓、“赶拦刺张” 联合渔法等 捕捞效率很高, 导致凶猛性鱼类数量的不断减少, 而捕食者的减少使鳑鲏等小型鱼类种群数量增多. 牛山 湖西片的红鯺原鲌、鲭鱼和黄颡鱼的数量比中片多 (表 5), 这些鱼的大量存在控制了小型鱼类的过度增长, 使其种群数量维持在较低的水平.

\section{3 牛山湖小型鱼类的空间分布}

鱼类群落结构与生境的异质性密切相关,在相似的生境中鱼类群落组成也常相似,许多鱼类仅在特定 的生境中出现,鱼类在湖泊中的空间分布与生境因子具有一定的相关性 ${ }^{[10]}$, 主要生境因子包括水生植物、 距湖岸距离、水深、透明度、底质特点、溶氧条件等.

本研究中牛山湖各片有水草生境渔获物数量显著比无水草生境多,小型鱼类喜欢分布在水草生境中, 这可能与小型鱼类的摄食和捕食压力有关. 根据最适摄食理论, 鱼类权衡被食压力和摄食效率的关系, 选 择最适生境使被食死亡率与摄食效率的比值最低 ${ }^{[11]}$. 小型鱼类主要以藻类、浮游动物、水生昆虫、虾类、水 生植物等作为食物, 而这些食物在水草生境中分布较多,形成复杂的食物网, 因此在此食物网中小型鱼类作 为顶级消费者, 可占据有利生态位, 充分获得所需食物. 从另一方面看, 牛山湖的肉食性鱼类较多, 主要是 乌鳢、红鯺原鲌、尧嘴鲌、鳜、黄颡鱼等, 约占总鱼产量的 $1 / 3$ (表 5), 巨大的捕食压力也迫使小型鱼类寻找水 
草生境作为隐蔽和保护场所. 因此牛山湖小型鱼类喜欢选择水草生境与其生存策略是密切相关的. Mattila 等 ${ }^{[12]}$ 研究也表明鱼类数量在苦草生境中比无水生植被生境多, 因为苦草生境与无水生植被生境相比不但 增加了生境的复杂性而且提供了栖息和躲藏的场所 ${ }^{[13]}$.

\section{4 牛山湖小型鱼类资源的利用}

小型鱼类是长江中下游湖泊鱼类群落的重要组成部分, 种类众多, 资源量相当丰富,在湖泊的能量流动 和物质循环中具有十分重要的作用, 小型鱼类摄食湖中大量的饵料资源, 同时与许多经济鱼类竞争食物和 空间 ${ }^{[14]}$, 因此应该合理利用这些小型鱼类资源, 防止其种群过度增长.

小型鱼类的经济价值相对较低,而目前凶猛性鱼类的市场需求较大, 经济价值较高, 因此通过食物链将 小型鱼类作为凶猛性鱼类的饵料资源, 将其转化为优质鱼产品, 是个较好的解决办法. 这也可在一定程度 上缓解湖泊中经济鱼类在食物和空间上受到小型鱼类的竞争压力, 有利于提高湖泊经济效益和生态效益.

牛山湖中片小型鱼类数量最多,而且黑鯺鳈、棒花鱼、似鱎、麦穗鱼和鳑鲏以 1 龄鱼为主,因此可适当加 大凶猛性鱼类苗种的投放量, 有利于充分利用小型鱼类资源, 而其它两片小型鱼类的数量相对较少,应适当 控制凶猛性鱼类苗种的投放量. 另外对小型鱼类资源也要加以保护, 可加大捕捞网具的网目规格 $(2 \mathrm{~cm}$ 以 上). 小型鱼类主要栖息于沉水植物生境,因此应加强对沉水植物的保护,防止被过度开发.

\section{4 参考文献}

[1] Carpenter S R, Kitchell J F. Consumer control of lake productivity. Bioscience, 1988, 38:764 - 769.

[2] Van L L, Gulati R D. Restoration and recovery of shallow eutrophic lake ecosystems in the Netherlands: epilogue. Hydrobiologia, 1992, 233:283 - 287.

[3] Zippin C. An evaluation of the removal method of estimating animal population. Biometrics, 1956, 12: 163 $-189$.

[4] Morgan R P. Modified popnet design for collecting fishes in varying depths of submersed aquatic vegetation. J Fresh Ecol, 1988, 4:533 - 539.

[5] Brian R M, David W W. Fishiries techniques. USA, American Fisheries Society, 1996.

[6] 谢松光, 李钟杰, 崔奕波. 用围网标志回捕法研究草型湖泊小型鱼类的密度. 水生生物学报, 2003,27 (1) :98-99.

[7] Xie S, Cui Y, Li Z. Spatial pattern of small fishes in the Niushanhu Lake in spring. 水生生物学报, 1999, 23 (Suppl) : $181-186$.

[8] Dewey M R, Holland-Bartels L E, Zigler S J. Comparison of fish catches with buoyant popnets and seines in vegetated and nonvegetated habitats. N Amer J fish Manag, 1989, 9: 249 - 253.

[9] Xie S, Cui Y, Li Z. Small Fish communities in two regions of the Liangzi Lake, China, with or without submersed macrophytes. J Appl Ichthyol, 2000,451 - 453.

[10] Gaudrear N, Boisclair D. The influence of spatial heterogeneity on the study of fish horizontal daily migration. Fish Res, 1998, 35: $65-73$.

[11] Turner A M, Mittelbach G G. Predator avoidance and community structure: interactions among piscivores. Planktivores Plankton Ecol, 1990,71 : 2241 - 2254.

[12] Mattila J, Chaplin G, Eilers M R. Spatial and diurnal distribution of invertebrate and fish fauna of a Zostera marina bed and nearby unvegetated sediments in Damariscotta River, Maine(USA). J Sea Res, 1999, 41 : $321-332$.

[13] Adams S M. The ecology of eelgrass, Zostera marina, fish communities structural analysis. J Exp Mar Biol Ecol, 1976, 22 : $269-291$.

[14] 方榕乐,张堂林,刘伙泉. 保安湖鱼类区系结构特点及其渔业利用. 见: 梁彥龄,刘伙泉编. 草型湖泊 资源、环境与渔业生态学管理 (一). 北京:科学出版社, 1995: $205-210$. 